\title{
O TRABALHO DO TUTOR EM UMA INSTITUIÇÃO PÚBLICA DE ENSINO SUPERIOR
}

Valdelaine Mendes*

Resumo: Este estudo tem como objetivo analisar as características do trabalho desempenhado por um dos profissionais que atuam no Ensino a Distância (EAD), o tutor, e identificar se esse trabalho pode ser definido como uma substituição da função docente no processo de formação. A pesquisa contou com dois procedimentos de investigação que se complementaram: um estudo dos registros legais e estatísticos referentes ao EAD e uma pesquisa qualitativa, do tipo estudo de caso. A investigação demonstrou que todas as atribuições dos tutores são encargos docentes. Há, dessa forma, uma substituição do professor pelo tutor, que, mesmo exercendo funções docentes, não possui vínculo empregatício; titulação compatível com as exigências para a docência no ensino superior; atuação com pesquisa e extensão. $\mathrm{O}$ trabalho no EAD é fragmentado entre aqueles que planejam e organizam as disciplinas, os "professores", e aqueles que as executam, interagindo (virtualmente) com os alunos, os "tutores".

Palavras-chave: Professor. Tutor. Trabalho. Ensino a Distância.

\section{THE WORK OF THE TUTOR IN PUBLIC INSTITUTIONS OF HIGHER EDUCATION}

ABSTRACT: This study aims to analyze the characteristics of the work performed by one of the professionals having a role in distance learning (DL), namely, the tutor, and to identify whether his/her work can be recognized as a substitution for the teaching function in the educational process. The research included two investigative procedures that complemented each other: a study of legal records and statistics for the DL and a piece of qualitative research of the case study kind.The investigation demonstrated that all assignments carried out by the tutors are teaching functions. In this sense, the tutor successfully replaces the teacher, practicing the same teaching functions, despite not having any employment contract, nor titles compatible with the requirements for teaching in university and not conducting university research and extension. The teaching work in distance learning is divided between those who plan and organize the courses, the "teachers" and those who execute them, the "tutors"; it is the tutors, not the teachers, that interact (virtually) with the students.

Keywords: Teacher. Tutor. Work. Distance Learning.

\footnotetext{
* Doutora em Educação pela Universidade de São Paulo (USP) e Professora adjunta da Universidade Federal de Pelotas (UFPel). Pesquisadora do Conselho Nacional de Desenvolvimento Científico e Tecnológico (CNPq). E-mail: valrosamendes@uol.com.br
} 


\section{Introdução}

Ao se abrir um jornal ou circular pelas ruas de cidades de médio e grande porte, é cada vez mais comum encontrar anúncios de instituições de ensino ofertando vagas nas diferentes modalidades do Ensino a Distância (EAD) ${ }^{1}$. Embora tal oferta prevaleça nas instituições privadas, as públicas também participam, de forma acentuada, desse processo, em especial, com a instituição da Universidade Aberta do Brasil (UAB), pelo Decreto n. 5.800, de 8 de junho de 2006.

Nas instituições privadas brasileiras, o EAD é oferecido a partir da autorização dada pelo Ministério da Educação (MEC). Nas instituições públicas, os cursos a distância vinculam-se ao Programa Pró-Licenciatura e ao sistema UAB. O Programa Pró-Licenciatura é voltado para a formação inicial a distância de professores em serviço. Atualmente, esses cursos estão vinculados ao sistema UAB. Esse programa é coordenado pela Secretaria da Educação Básica do MEC, em articulação com a Secretaria de Educação a Distância. A UAB reúne todos os cursos oferecidos nas instituições públicas do país e está lotada na Coordenação de Aperfeiçoamento de Pessoal de Nível Superior (Capes), instituição que, tradicionalmente, atua na pós-graduação stricto sensu e no apoio à produção científica no país.

Uma leitura inicial dos primeiros documentos de criação da UAB já indicava uma clara flexibilização nos requisitos dos profissionais que coordenariam e conduziriam os cursos na modalidade a distância. Três aspectos contidos nesses materiais podem aqui ser recuperados: a não menção ao tripé ensino, pesquisa e extensão como condição central da formação universitária; a possibilidade de exercício docente nos cursos sem uma previsão de professores com titulação, como a exigida nos cursos presenciais; e, talvez a mais grave, a indicação de que o vínculo dos profissionais que atuariam em cursos a distância poderia ocorrer por meio de bolsas, e não por contrato formal de trabalho. Entretanto, vale lembrar que, nas modalidades a distância, deverão ser obedecidos os mesmos critérios definidos na legislação para a constituição de uma instituição de ensino superior, seja uma faculdade, um centro universitário ou uma universidade ${ }^{2}$.

Essas leituras impulsionaram a realização deste estudo, que tem como objetivo analisar as características do trabalho desempenhado por 
um dos profissionais que atuam no EAD, o tutor, e identificar se esse trabalho pode ser definido como uma substituição da função do docente no processo de formação. A pesquisa contou com dois procedimentos de investigação que se complementaram: um estudo dos registros legais e estatísticos referentes ao EAD e uma pesquisa qualitativa, do tipo estudo de caso.

Com o estudo dos registros de documentos, pretendeu-se realizar um levantamento de toda a legislação referente ao EAD no Brasil, para compreender quais são os aparatos legais dessa modalidade de ensino no país. Já a investigação qualitativa, do tipo estudo de caso, foi desenvolvida em uma Instituição Pública Federal de Ensino Superior (IPFES) da região Sul do Brasil. Esse tipo de estudo é realizado a partir de um pequeno universo de investigação, mas com grande número de variáveis. Para Stake (1983), o pesquisador qualitativo observa como os eventos são determinados, no contexto em que ocorrem.

Para a realização do estudo foi feito levantamento do número de cursos na modalidade EAD oferecidos pela IPFES. Logo após, foram verificados quem são e como atuam os tutores desses cursos e, a partir daí, iniciou-se o processo de realização das entrevistas. Nessa parte da pesquisa, foram utilizadas entrevistas semiestruturadas, por permitirem ao pesquisador ter um roteiro de questões para orientar seu diálogo com o entrevistado, sem, entretanto, impedir a inclusão ou a exclusão de pontos que sejam pertinentes ao estudo. Foram entrevistados oito tutores, sendo dois de cada curso oferecido pela instituição pesquisada. Os critérios para a escolha dos participantes do estudo foram: maior tempo de trabalho com EAD e disponibilidade para responder às questões da pesquisa.

Este texto está organizado em três partes. Em um primeiro momento, foi feita uma discussão sobre a normatização do EAD, com o intuito de localizar, nos documentos legais, a definição do papel do tutor. Em um segundo momento, já dialogando com os dados levantados na pesquisa, são discutidas as funções e as tarefas do tutor no EAD. Por fim, buscam-se os pontos de aproximação entre o trabalho do tutor ${ }^{3}$ e o trabalho docente. 


\section{A normatização do ensino ${ }^{4}$ a distância no Brasil}

Em meados do século XX, já se podia realizar cursos a distância no Brasil. Em geral, tais cursos tinham como finalidade a formação profissionalizante e eram realizados com material enviado pelos Correios. $\mathrm{O}$ Instituto Universal Brasileiro, fundado em 1941, foi um dos pioneiros nessa modalidade de ensino no país e, até hoje, oferece cursos em diferentes áreas, recorrendo tanto aos Correios quanto à internet para interagir com os estudantes.

A diferença fundamental entre os cursos oferecidos até o final dos anos 1990 e os que se tem na atualidade está, justamente, no tipo de ensino que era ofertado. Se, anteriormente, os cursos tinham como finalidade permitir a aprendizagem de determinada técnica (mecânica, costura, eletrônica, etc), hoje, eles habilitam profissionais em diferentes áreas e níveis de graduação.

Com o intuito de situar o trabalho do tutor no EAD na legislação educacional, recorreu-se a um conjunto de leis, decretos e portarias sobre a normatização da educação no Brasil desde o final do século XIX. Essa revisão da legislação educacional indicou que a primeira lei que faz menção ao ensino a distância só foi aprovada em 1996.

As duas primeiras leis de diretrizes e bases da educação nacional elaboradas no Brasil, a Lei n. 4.024/1961 e a Lei n. 5.692/1971, bem como a Lei n. 5.540/1968, que, especificamente, fixava normas para o ensino superior, não fazem qualquer referência às modalidades de ensino que não sejam presenciais. $O$ único documento que faz menção a esse tipo de ensino é o Decreto n. 1.044/1969, que dispõe sobre a realização de atividades domiciliares em casos especiais, ou seja, trata-se da garantia legal do acesso à educação a pessoas portadoras de algum tipo de afecção. Nesse caso, é uma excepcionalidade possibilitada pela lei, apenas para pessoas em condição especial, e não caracteriza um tipo ou modalidade de ensino.

O artigo 80 da Lei n. 9394/96, a Lei de Diretrizes e Bases da Educação Nacional (LDB), em vigência, define que "o poder público incentivará o desenvolvimento e a veiculação de programas de ensino a distância, em todos os níveis e modalidades de ensino e de educação continuada". De acordo com a lei, a autorização para o funcionamento desses programas caberá aos sistemas de ensino, sendo possível a cooperação 
entre os mesmos. O conteúdo do artigo indica que qualquer nível de formação poderá ser desenvolvido a distância, o que significa a possibilidade de oferta de ensino, nesse formato, dos níveis mais elementares à pós-graduação ${ }^{5}$.

O Decreto n. 2.494, de 10 de fevereiro de 1998, regulamenta o artigo 80 da LDB e detalha, em treze artigos, a caracterização, a certificação e a avaliação dessa modalidade de ensino. Nesse decreto, a educação a distância é definida como "uma forma de ensino que possibilita a autoaprendizagem, com a mediação de recursos didáticos sistematicamente organizados, apresentados em diferentes suportes de informação, utilizados isoladamente ou combinados, e veiculados pelos diversos meios de comunicação". A organização dos cursos nessa modalidade será "em regime especial, com flexibilidade de requisitos para admissão, horários e duração". O Decreto n. 2.561, de 27 de abril de 1998, altera a redação de dois artigos do Decreto n. 2.494 referentes à esfera (municipal, estadual ou federal) responsável pelo credenciamento de instituições para a oferta de cursos a distância.

Alguns anos após a elaboração dos Decretos n. 2.494 e 2.561, o Decreto n. 5.622, de 19 de dezembro de 2005, revoga as determinações de 1998 e cria uma nova regulamentação para o artigo 80 da LDB, distribuída em 37 artigos, bem mais detalhada que a constante nos decretos anteriores. Esse decreto apresenta outra caracterização para a educação a distância, definindo-a como uma modalidade educacional "na qual a mediação didático-pedagógica nos processos de ensino e aprendizagem ocorre com a utilização de meios e tecnologias de informação e comunicação, com estudantes e professores desenvolvendo atividades educativas em lugares ou tempos diversos".

A caracterização do Decreto de 2005 apresenta uma diferença importante em relação aos documentos de 1998, na medida em que retira a expressão "auto-aprendizagem" do texto e coloca o professor juntamente com o estudante no centro do processo de ensino.

O Decreto n. 5.622 prevê que as avaliações e algumas atividades (quando previstas na legislação pertinente), como estágios, defesas de trabalhos de conclusão de curso e trabalhos em laboratórios, sejam presenciais. Tais atividades são feitas no polo de apoio presencial, que é definido como "unidade operacional, no País ou no exterior, para o desenvolvimento descentralizado de atividades pedagógicas e adminis- 
trativas relativas aos cursos e programas ofertados a distância" (Artigo 12 , inciso $\mathrm{X}$, alínea ' $c$ '). As demais atividades previstas no curso podem ser feitas a distância.

Em relação à equipe de professores, consta no decreto, no artigo 12, inciso VIII, que a instituição deve "apresentar corpo docente com as qualificações exigidas na legislação em vigor e, preferencialmente, com formação para o trabalho com educação a distância". Disso depreende-se que, na educação superior, de acordo com as características da instituição (universidades, centros universitários ou faculdades), o percentual de professores qualificados com mestrado ou doutorado deverá ser o mesmo do ensino presencial, bem como todas as demais exigências para a abertura dos cursos.

O Decreto n. 5.622 conserva a redação do Decreto n. 2.494, de 1998, ao mencionar a figura de outro profissional no ensino a distância: o tutor. Trata-se de um elemento que é mencionado nos decretos, sem que se tenha qualquer caracterização da sua função. A análise do conjunto de documentos legais aqui levantados permite inferir que esse profissional tem como funções: auxiliar o aluno que estuda a distância, esclarecendo suas dúvidas; buscar materiais de apoio; e realizar a mediação entre o professor e o estudante. É esse o profissional que estará tanto nos polos presenciais quanto nos polos a distância para atender os estudantes.

Os únicos documentos legais em que foi possível encontrar maior detalhamento do papel do tutor no ensino a distância foram os Pareceres n. $195^{6}$, de 12 de julho de 2007, e 1977, de 8 de novembro de 2007, do Conselho Nacional de Educação. Esses pareceres versam sobre os instrumentos de avaliação para o credenciamento de instituições de educação superior, para oferta de cursos superiores na modalidade a distância. Neles, há toda uma pontuação que será atribuída à entidade de ensino superior, em cada quesito de avaliação (estrutura física, corpo técnico, corpo docente, estrutura pedagógica, etc) e que será usada para credenciar ou não uma instituição que oferece esse tipo de ensino.

Do ponto de vista da política educacional, esses documentos são extremamente importantes, pois definem o que será considerado mais ou menos relevante na criação, na conservação ou no fechamento de um curso. São indicadores que acabam por se tornar definidores das ações em uma instituição de ensino. 
$\mathrm{Na}$ análise desses documentos, percebeu-se que eles são bastante genéricos em relação a uma questão fundamental no exercício docente: a relação número alunos/professor. $\mathrm{O}$ mesmo acontece em relação ao número de alunos por tutor. Sobre essa questão, no Parecer n. 197, a pontuação mais alta, no item condições de trabalho, é atribuída quando "essa relação está plenamente adequada e coerente com a proposta de atividades para os conteúdos (disciplina, módulo, etc) e apresenta de forma equilibrada o binômio quantidade/qualidade no atendimento, incluindo flexibilidade no horário".

Nesse aspecto, não fixar parâmetros que indiquem o que seria um número adequado de alunos por professor ou tutor (mesmo resguardando as especificidades de cada área) significa deixar nas mãos da instituição de ensino ou dos avaliadores a responsabilidade por definir o que é mais ou menos adequado. No caso das instituições privadas de ensino, que visam ao lucro, o "mais adequado" pode ser uma relação bem elevada professor/aluno ou tutor/aluno.

O Parecer n. 197 é o documento que melhor detalha as características do tutor e sua necessária formação. $\mathrm{O}$ texto menciona que a instituição receberá uma nota menor na avaliação, no quesito qualificação dos tutores, "quando menos de 50\% dos tutores previstos para a primeira metade do curso são graduados ou a atuação de cada um no curso não é condizente com a respectiva formação acadêmica”. Isso significa, então, ser possível que o tutor não tenha formação nem em nível de graduação, ou seja, tenha formação menor do que aquela na qual trabalha.

Com o Decreto n. 5.800, de 8 de junho de 2006, foi criada a Universidade Aberta do Brasil (UAB), com o objetivo de "ampliar e interiorizar a oferta de cursos e programas de educação superior, por meio da educação a distância", nas instituições públicas de ensino (BRASIL, 2010). Na Resolução n. 8, de 30 de abril de 2010, do Conselho Deliberativo do Fundo Nacional de Desenvolvimento da Educação (FNDE), que define os valores pagos a cada profissional que desempenha funções no EAD na UAB, há um detalhamento dos requisitos necessários ao exercício de cada função, nessa modalidade de ensino. Optou-se por expor o artigo $9^{\circ}$ da referida resolução para mostrar como se constituem as equipes de trabalho no EAD, na UAB, e qual o lugar do tutor nessa estrutura, bem como a remuneração percebida por cada um. 
I - Coordenador/Coordenador-adjunto da UAB: professor ou pesquisador indicado pelas IPES vinculadas ao Sistema UAB, que atuará nas atividades de coordenação e apoio aos pólos presenciais e no desenvolvimento de projetos de pesquisa relacionados aos cursos e programas implantados no âmbito do Sistema, desde que comprove a experiência de, no mínimo, três anos de magistério superior. O valor da bolsa a ser concedida é de $\mathrm{R} \$ 1.500,00$ (um mil e quinhentos reais) mensais, enquanto exercer a função (Coordenador/ Coordenador adjunto I). Aquele que não comprovar essa experiência, mas que tenha formação mínima em nível superior e experiência de 1 (um) ano no magistério superior, ou a formação ou a vinculação em programa de pós-graduação de mestrado ou doutorado, receberá bolsa no valor de $\mathrm{R} \$ 1.100,00$ (um mil e cem reais) mensais e ficará vinculado como Coordenador/ Coordenador adjunto II.

II - Coordenador de curso nas instituiçães públicas de ensino superior (IPES): professor ou pesquisador designado/indicado pelas IPES vinculadas ao Sistema UAB, que atuará nas atividades de coordenação de curso implantado no âmbito do Sistema UAB e no desenvolvimento de projetos de pesquisa relacionados aos cursos, desde que comprove a experiência de, no mínimo, três anos de magistério superior. O valor da bolsa a ser concedida é de $\mathrm{R} \$ 1.400,00$ (um mil e quatrocentos reais) mensais, enquanto exercer a função (Coordenador de curso I). Aquele que não comprovar essa experiência, mas que tenha formação mínima em nível superior e experiência de 1 (um) ano no magistério superior, ou a formação ou a vinculação em programa de pós-graduação de mestrado ou doutorado, receberá bolsa no valor de $\mathrm{R} \$ 1.100,00$ (um mil e cem reais) mensais e ficará vinculado como Coordenador de curso II.

III - Coordenador de tutoria nas instituições públicas de ensino superior (IPES): professor ou pesquisador designado/indicado pelas IPES vinculadas ao Sistema UAB, que atuará nas atividades de coordenação de tutores dos cursos implantados no âmbito do Sistema UAB e no desenvolvimento de projetos de pesquisa relacionados aos cursos, desde que comprove a experiência de, no mínimo, três anos de magistério superior. O valor da bolsa a ser concedida é de $\mathrm{R} \$ 1.300,00$ (um mil e trezentos reais) mensais, enquanto exercer a função (Coordenador de tutoria I). Aquele que não comprovar essa experiência, mas que tenha formação mínima em nível superior e experiência de 1 (um) ano no magistério superior, ou a formação ou a vinculação em programa de pós-graduação de mestrado ou doutorado, receberá bolsa no valor de $\mathrm{R} \$ 1.100,00$ (um mil e cem reais) mensais, e ficará vinculado como Coordenador de tutoria II.

IV - Professor-pesquisador conteudista: professor ou pesquisador designado ou indicado pelas IPES vinculadas ao Sistema UAB, que atuará nas atividades de elaboração de material didático, de desenvolvimento de projetos e de pesquisa, relacionadas aos cursos e programas implantados no âmbito do Sistema, sendo exigida experiência de 3 (três) anos no magistério superior. $\mathrm{O}$ valor da bolsa a ser concedida é de $\mathrm{R} \$ 1.300,00$ (um mil e trezentos reais) mensais, 
enquanto exercer a função (Professor-pesquisador I). Aquele que não comprovar essa experiência, mas que tenha formação mínima em nível superior e experiência de 1 (um) ano no magistério superior, ou a formação ou a vinculação em programa de pós-graduação de mestrado ou doutorado, receberá bolsa no valor de $\mathrm{R} \$ 1.100,00$ (um mil e cem reais) mensais e ficará vinculado como Professor-pesquisador II.

V - Professor-pesquisador: professor ou pesquisador designado ou indicado pelas IPES vinculadas ao Sistema UAB, que atuará nas atividades típicas de ensino, de desenvolvimento de projetos e de pesquisa, relacionadas aos cursos e programas implantados no âmbito do Sistema UAB, sendo exigida experiência de 03 (três) anos no magistério superior. $O$ valor da bolsa a ser concedida é de $\mathrm{R} \$ 1.300,00$ (um mil e trezentos reais) mensais, enquanto exercer a função (Professor-pesquisador I). Aquele que não comprovar essa experiência, mas que tenha formação mínima em nível superior e experiência de 1 (um) ano no magistério superior, ou a formação ou a vinculação em programa de pós-graduação de mestrado ou doutorado, receberá bolsa no valor de $\mathrm{R} \$ 1.100,00$ (um mil e cem reais) mensais e ficará vinculado como Professor-pesquisador II.

VI - Tutor: profissional selecionado pelas IPES vinculadas ao Sistema UAB para o exercício das atividades típicas de tutoria, sendo exigida formação de nível superior e experiência mínima de 1 (um) ano no magistério do ensino básico ou superior, ou ter formação pós-graduada, ou estar vinculado a programa de pós-graduação. O valor da bolsa a ser concedida é de $\mathrm{R} \$ 765,00$ (setecentos e sessenta e cinco reais) mensais, enquanto exercer a função. Cabe às IPES determinar, nos processos seletivos de tutoria, as atividades a serem desenvolvidas para a execução dos Projetos Pedagógicos, de acordo com as especificidades das áreas e dos cursos.

VII - Coordenador de pólo: professor da rede pública, graduado e com, no mínimo, 3 (três) anos em magistério na educação básica ou superior, responsável pela coordenação do pólo de apoio presencial. O valor da bolsa a ser concedida é de $\mathrm{R} \$ 1.100,00$ (um mil e cem reais) mensais, enquanto exercer a função.

Com esse detalhamento das funções desempenhadas por cada profissional na UAB, é possível perceber que o tutor é o trabalhador com menor remuneração. Além disso, para o exercício da função, basta possuir nível superior e experiência de um ano no magistério. São os mesmos requisitos exigidos dos profissionais que atuarão nas funções de "coordenação de tutoria 2", "pesquisador 2" e "professor-pesquisador conteudista”. A resolução não define se o tutor deve ter formação na mesma área em que atuará. Vale reiterar que a estrutura definida pela Resolução n. 8, do FNDE, é válida somente para instituições públicas de ensino que oferecem cursos a distância no sistema UAB. 
Um aspecto importante identificado na revisão da legislação é que algumas áreas estão sujeitas à autorização específica para a oferta de cursos em nível superior a distância. No artigo 23 do Decreto n. 5.622, consta: "A criação e autorização de cursos de graduação a distância deverão ser submetidas, previamente, à manifestação do: 1) Conselho Nacional de Saúde, no caso dos cursos de Medicina, Odontologia e Psicologia; ou 2) Conselho Federal da Ordem dos Advogados do Brasil, no caso dos cursos de Direito".

Se o objetivo dos cursos a distância é justamente levar formação em nível superior para aquelas localidades onde não há IES ou para aquelas pessoas que não tenham a possibilidade de frequentá-las, ficam os questionamentos: por que, em algumas áreas, os conselhos profissionais deverão ser ouvidos antes da oferta de um curso superior? Será que na Medicina, na Odontologia, na Psicologia ou no Direito já existem, em todos os rincões do Brasil, profissionais em número suficiente para que essas áreas não precisem ser ampliadas e interiorizadas, conforme os argumentos do MEC para a oferta de EAD? Ou será que algumas áreas precisam de mais tempo para avaliar a viabilidade e a pertinência da oferta de cursos em nível superior a distância, diferentemente do que vem ocorrendo, por exemplo, na área de formação de professores? De fato, os dados da Sinopse do MEC do Ensino Superior de 2008 (BRASIL, 2010) comprovam a inexistência de cursos superiores a distância nessas áreas, em todo o país.

\section{As funções e as tarefas do tutor no EAD}

Como já mencionado, no EAD há a figura de um profissional que não se encontra em outras formas de ensino no Brasil, que é o "tutor". Na instituição investigada, em um edital para seleção de tutores para o EAD, aparecem as atribuições que cabem a esse profissional. Tratase de ações que estão muito próximas das responsabilidades de um professor. São elas:

a) Mediar a comunicação de conteúdos entre o professor e os cursistas;

b) Acompanhar as atividades discentes, conforme o cronograma do curso;

c) Apoiar o professor da disciplina no desenvolvimento das atividades docentes; 
d) Manter regularidade de acesso ao AVA e dar retorno às solicitações do cursista no prazo máximo de 24 horas;

e) Estabelecer contato permanente com os alunos e mediar as atividades discentes;

f) Colaborar com a coordenação do curso na avaliação dos estudantes;

g) Participar das atividades de capacitação e atualização promovidas pela Instituição de Ensino;

h) Elaborar relatórios mensais de acompanhamento dos alunos e encaminhar à coordenação de tutoria;

i) Participar do processo de avaliação da disciplina sob orientação do professor responsável;

j) Apoiar operacionalmente a coordenação do curso nas atividades presenciais nos pólos, em especial na aplicação de avaliações.

Ainda, de acordo com o referido edital, são requisitos para ser tutor: possuir titulação específica condizente com o curso de atuação; disponibilidade para viagens aos polos de abrangência do curso durante a semana, inclusive aos sábados e domingos; conhecimentos básicos para manuseio de computador, internet e disponibilidade para aprendizagem de ferramentas para o EAD. Embora não conste no edital, o tutor deve dedicar 20 horas semanais ao EAD.

Há dois tipos de tutores no EAD: presencial e a distância. O tutor presencial permanece na cidade polo e tem como função principal ajudar os alunos na realização das tarefas, auxiliá-los na mediação com os professores e tutores a distância e assisti-los no uso dos equipamentos de informática. Já o tutor a distância permanece na cidade sede da instituição superior de ensino que oferece o curso e realiza exatamente as funções previstas no edital. Em cada polo há dois tutores presenciais e dois tutores a distância, por curso.

Neste estudo, a investigação centrou-se apenas nos tutores a distância pelo entendimento de que a maior parte das funções previstas no edital é desempenhada pelo tutor a distância, ficando o tutor presencial, de acordo com informações levantadas durante a pesquisa, mais responsável por tarefas burocráticas e por prestar auxílio no uso dos equipamentos de informática.

As entrevistas revelaram uma variedade de características dos trabalhos realizados pelos tutores a distância que, em cada curso, podem possuir funções distintas. De acordo com os dados da pesquisa, o tutor pode: a) ser responsável por uma disciplina em um ou dois polos; b) ser 
responsável por uma disciplina, mas atender vários polos ao mesmo tempo; c) não ter uma disciplina específica e ser responsável por um polo, ou seja, responder por todas as disciplinas que são ofertadas; d) atuar em um polo diferente em cada semestre.

Como a estrutura da formação a distância na instituição pesquisada é recente, os cursos ainda estão em fase de formulação e ajustes. Durante as entrevistas, os tutores revelaram que mudanças vêm ocorrendo desde quando ingressaram, o que parece normal em projetos novos. Tais reformulações são feitas, conforme os relatos, com o intuito de melhorar o trabalho e, consequentemente, a formação dos estudantes.

Vera $^{9}$, uma das tutoras entrevistadas, revelou ter havido uma mudança na organização do curso em que trabalha, pois até o último ano cada tutor se dedicava a várias disciplinas e a um número menor de polos. Atualmente, o tutor dedica-se a uma disciplina, mas a um número maior de polos. Sobre essa questão a tutora mencionou:

porque a gente se dedica só àquela disciplina, mesmo que seja para vários polos. Já está mais por dentro do assunto, não precisa ler outras coisas, de várias disciplinas ao mesmo tempo, sendo que tu tens só aquilo ali, tu só vai atender um número maior de pessoas, mas é para uma disciplina só.

A quantidade de disciplinas que estão sob a responsabilidade do tutor é uma questão importante, pois quanto mais disciplinas mais tempo de preparação e estudo ele precisará para dar conta das demandas dos alunos. Isso se torna ainda mais preocupante quando o tutor atua em um curso diferente daquele em que teve sua formação inicial, situação vivida por metade dos tutores entrevistados.

Uma tutora afirmou que, até o momento da entrevista, já havia trabalhado com sete disciplinas diferentes no curso. Já Carlos relatou que, no seu curso, o tutor

atua em um polo em todas as disciplinas daquele semestre e divide com outro tutor a turma. Cada um fica com metade dos alunos. Dos 25 alunos que eu tinha quando começou, hoje tem 18. [...] em um semestre são trabalhadas 6 ou 7 disciplinas. A duração das disciplinas varia, pode ser de duas até cinco semanas. Isso depende da carga horária que foi prevista para aquela disciplina.

Carlos afirmou que trabalha no polo com todas as disciplinas do curso. Quando questionado sobre a dificuldade para realizar tal tarefa, já 
que precisa responder por um leque grande de conteúdos, além do fato de o curso em que atua não ser o mesmo de sua formação inicial, disse:

É complicado. Na verdade, até então, a gente não tem disciplinas muito específicas, elas são bem amplas, bem abrangentes, não tem nada que seja pontual, "assim ah agora nós vamos discutir sobre como se dá, alguma coisa pontual do campo" [...] É complicado porque tu tens que dominar uma coisa muito ampla.

É comum em um curso presencial, quando são ofertadas, por exemplo, sete disciplinas, haver, respectivamente, sete docentes para ministrá-las. Na instituição pesquisada, é o que ocorre nos cursos presenciais. Isto é, cada professor, de acordo com sua formação e perfil, assume a responsabilidade por determinada disciplina. Realidade bastante diferente da encontrada nos relatos dos tutores. Embora, normalmente, em um curso de graduação, as disciplinas possuam ementas que se complementam e se articulam, sabe-se que o domínio de todos os conteúdos de um currículo é algo bastante complexo para um profissional.

Osmar, que já trabalhou com quatro disciplinas, atualmente trabalha com apenas duas, mas em vários polos. Ele afirmou que, no seu curso, o tutor monta exercícios e questões que o professor pesquisador "pode aproveitar para usar nas provas, nas tarefas". As provas são, em geral, elaboradas pelo professor pesquisador, responsável pela estruturação da disciplina, mas são corrigidas pelos tutores, assim como ocorre com as tarefas. Em média, no curso de Osmar, cada tutor fica com 30 alunos por polo.

Encontrou-se ainda o caso de Isaura, que tem uma graduação, mas é tutora em outra. Ela revelou sua vontade de realizar o curso no qual trabalha e, com a tutoria, poder unir o desejo de ensinar e aprender sobre a área. Quando questionada sobre as dificuldades em lidar com conteúdos a que não teve acesso, ao longo de sua formação, respondeu:

eu tenho uma ansiedade muito grande com relação a isso [...]. Então quando eu vim pra trabalhar eu vim com essa expectativa, como ia ser. Então, inicialmente, as gurias têm um trabalho aqui bem diferenciado, elas buscam que os professores tenham um comprometimento, a responsabilidade. Acho que não é só o conteúdo de sala de aula porque eu não posso dar o conteúdo isoladamente, que eu tenho que buscar aquilo que pro aluno é importante. 
Isaura fala em trabalhar na formação daquilo que, para o aluno, é importante. Indubitavelmente, essa é uma questão central em qualquer processo educativo, na medida em que aos conhecimentos trabalhados são incorporados os desejos, interesses e sonhos dos estudantes. Porém, essa forma de ensinar não exime o professor da sua responsabilidade de dominar os conteúdos específicos com os quais atuará, o que pressupõe formação adequada na respectiva área de exercício da docência. Durante a entrevista, os argumentos de Isaura revelaram uma tentativa de compensar as dificuldades com essa dimensão mais específica do trabalho, referente aos conteúdos que são desenvolvidos em um curso, com uma postura comprometida e responsável com os alunos.

Evidentemente, não é possível reduzir o trabalho docente somente à dimensão de uma lista de temas que precisa ser vencida em uma disciplina, pois, como afirma Arroyo (2002), é preciso pensar na dinâmica histórica da aprendizagem humana e sobre qual projeto de sociedade e de ser humano debruçam-se os educadores. Isso significa que o conjunto de elementos adotado no processo de ensino-aprendizagem favorecerá uma formação voltada para a conservação ou superação das desigualdades e injustiças sociais.

De acordo com Fétizon e Minto (2007, p. 100):

a educação escolar não ocorre pelas simples circunstâncias sócio-culturais em ação na escola - logo, o desempenho do professor não pode ser aleatório, assim como seus resultados não podem ser fortuitos: ambos devem ser frutos de uma formação muito cuidadosa. E ensinar significa, em essência, potenciar a arte de pensar (inata, no ser humano e, portanto, no estudante), de construir concepções claras que se aplicam a experiências de primeira mão, selecionar informações relevantes, testar descobertas - logo, a formação do professor implica a posse do método científico e a capacidade de aumentar a chance de sua transferência para a experiência do educando.

A solução encontrada para os problemas educacionais no Brasil é, muitas vezes, a mais barata. Não é raro encontrar, nas escolas brasileiras, professores habilitados em uma área atuando em outra. Um professor de matemática assume aulas de artes, o de educação física assume biologia, o de história trabalha com português. Nesse caso, como fica a especificidade do conteúdo com o qual trabalham?

No caso dos tutores dos cursos de EAD estudados, foi justamente esse o quadro encontrado: pessoas com uma formação atuando em 
outra área. Apesar de manifestarem uma enorme disposição para aprender, inclusive com declarações de que seriam professores e alunos ao mesmo tempo, isso indica uma clara precarização do ensino e da formação a que têm acesso os estudantes de EAD. Considerando que quase a totalidade dos tutores tem uma jornada semanal de trabalho que ultrapassa 40 horas, é possível inferir que o tempo disponível dessas pessoas para estudar e se preparar para o trabalho como tutor é exíguo ou inexistente.

Em relação à organização das disciplinas, todos afirmaram que essa função fica com o professor formador. Cabe a esse profissional montar a disciplina que é apresentada aos alunos e aos tutores. A responsabilidade pela disciplina também é do professor formador. Carlos detalhou qual é a função desse professor:

na função do professor formador ele organiza essa disciplina, vê os conteúdos que vão ser trabalhados, o tempo que vai gerar essa disciplina, as tarefas que vão ser feitas nas disciplinas, como que vai se dar a disciplina. Ele monta a disciplina, põe no sistema Moodle, e é a partir dali que eu começo a trabalhar.

Com esse trecho, fica claro que o tutor não participa do processo de preparação das disciplinas que acompanhará. No caso de Carlos, uma semana antes do início da disciplina é disponibilizado material de apoio para os tutores. Ele afirmou:

Os textos que vão ser trabalhados na disciplina já estão lá ou então o referencial bibliográfico pra ti buscar e aí tem algumas sugestões de leituras, algumas coisas, aí tem o fórum de dúvidas, todos os professores, com os professores tutores com os professores formadores.

Rosa e outros tutores também citaram o fórum como um espaço a que recorrem para esclarecer as dúvidas que têm sobre o material disponibilizado pelo professor formador. Para esta tutora, são esses professores que têm a responsabilidade de realizar a postagem da disciplina no ambiente, são eles que "programam as aulas, são eles que organizam todo o material". Disse ainda que recebe o material junto com os alunos e "aí a gente participa de fóruns, a gente dá um retorno, discute com eles". Nesse caso, por receber o material juntamente com os alunos, não dispõe de um tempo de estudo e preparo para o trabalho que será desempenhado. 
Houve o caso da tutora Leila, que afirmou participar da organização da disciplina, mas isso tem mais a ver com o seu perfil do que com a demanda de sua função: "eu tenho boa vontade em ajudar, sabe? Então, nas disciplinas que eu trabalhei, agora, a maioria das provas, os professores, ah Leila, dá uma revisada, vê o que que tu achas, se tá bom”. Ela deixou bem claro que opina na organização das disciplinas por conta do seu perfil, o que também acontece com outros tutores. Entretanto, essa participação não é uma regra entre eles.

Essa não participação no processo de organização e elaboração da disciplina também foi apontada como uma dificuldade, pois muitas vezes o tutor não sabe exatamente quais são as intenções do professor que a elaborou. De acordo com Rosa:

é bem complicado porque tu tens que também imaginar qual é o objetivo do teu professor formador, né? O que ele quer, onde ele quer chegar? Então é leitura, tu tens que ler, tu tens que estudar, tu tens que também tentar fazer uma reflexão sobre o teu aluno. Era assim que eu fazia, estudava junto. Isso é muito legal. Essa parte da EAD é muito boa porque tu estudas o tempo inteiro.

Afirmou não interferir no trabalho do professor formador (responsável pela estruturação da disciplina e, formalmente, pelo acompanhamento dos alunos), mesmo quando identifica problemas ou dificuldades em um polo com o material enviado. Nos cursos estudados, há uma clara separação entre aqueles que programam a disciplina e aqueles que acompanham seu desenvolvimento. Como se viu, alguns tutores recebem o material alguns dias antes do início das aulas e outros recebem junto com os alunos. Será que a participação do tutor na elaboração da disciplina não seria uma forma de qualificar o seu trabalho? Será que essa participação eliminaria o trabalho do professor-formador? Essas questões estão na essência do EAD, pois são reveladoras da fragmentação do trabalho docente nesse modelo de ensino, em que alguns pensam o processo e outros o executam.

Evidenciou-se, então, que não cabe ao tutor a elaboração e a organização das disciplinas. Então, quais são as suas funções na instituição investigada? Carlos assim sintetizou a função do tutor: "a minha tarefa é cobrar dos alunos que eles façam a atividade, esclarecer o que que são as atividades, e depois avaliar essas atividades". Já Osmar lembrou do necessário acompanhamento do aluno no EAD: 
Nós temos a função de estar ali acompanhando os alunos, porque eles têm a oportunidade de tirar dúvidas, então nós temos que entrar, acessar normalmente, regularmente todos os dias pra ver se eles postaram alguma dúvida; aí nós temos que responder, ver que dúvida eles têm. A correção de tarefas, a correção de provas, acompanhar o aluno, como ele tá, se tá com dúvida ou não, que ele pode nos acessar, enviar a dúvida, que nós vamos retornar a resposta.

Leila falou especificamente sobre a correção de provas e afirmou que, no curso no qual atua, todos os tutores da disciplina podem responder às dúvidas que são apresentadas pelos alunos de qualquer polo, porém “a correção de tarefas e provas a gente tem um polo específico". Embora haja essa responsabilidade por um polo, os tutores das mesmas disciplinas acabam, muitas vezes, se ajudando para que as tarefas sejam cumpridas. A tutora ainda mencionou:

a gente acaba se ajudando porque a gente tem prazos, para entrega de notas. Até porque, as provas vêm pelo correio. [...] dependendo do polo a gente tem pouco tempo, tem um ou dois dias. Então, aquele professor não pode ficar responsável por dois ou três polos, então a gente tem que se ajudar.

Os tutores não elaboram as provas, mas, em alguns cursos, assumem a responsabilidade pela sua correção. Um entrevistado relatou que os tutores somente tiveram acesso à primeira prova aplicada no seu curso quando já estava impressa e após alguns polos já a terem realizado.

Pelos relatos, foi possível perceber que a principal função exercida pelos tutores foi a de auxiliar os alunos na realização das tarefas e na sua correção. De acordo com Carlos:

$\mathrm{Na}$ verdade a gente fica mais responsável pelas questões das tarefas. A tarefa é isso, tem que ter isso como resposta. Então a gente fica mais naquilo ali, mas aí a tarefa mexe com outras questões. [...] grande parte delas acaba mexendo com outras coisas, não só com aquele conteúdo, por exemplo, retoma a disciplina, cria biperlinks com outras disciplinas, então tu tens que tá indo e voltando a todo momento.

Para responder a uma dúvida e auxiliar o aluno na realização de uma tarefa, qualquer professor precisa dominar o conteúdo com o qual está trabalhando. Com os tutores aqui estudados, não são feitos questionamentos em tempo real (as dúvidas são postas no sistema), o que pode 
facilitar a elaboração de uma resposta sobre um conteúdo de menor domínio, já que o tutor pode pesquisar e buscar auxílio antes de enviar as respostas para o estudante.

Uma maior solicitação dos tutores ocorre quando se aproxima a data de entrega das tarefas ou de realização das provas. Osmar revelou que, fora desses períodos, não é muito solicitado pelos alunos para responder a dúvidas: "eu achava que seria bem mais".

Os tutores mencionaram que participam de reuniões com os pares e com os professores formadores, cuja periodicidade varia de curso para curso. Nessas reuniões, eles trocam informações sobre o andamento das atividades, esclarecem dúvidas e discutem as dificuldades encontradas. Conforme declarou Isaura: "nós temos, quinzenalmente, as reuniões presenciais e, nos intervalos, nós temos os chats $^{10}$, que é onde participam todos os professores, os tutores a distância e os presenciais".

Trata-se de um trabalho realizado, essencialmente, sobre tarefas que são apresentadas pelos alunos. Estas, em geral, são individuais, o que parece demandar um tempo significativo dos profissionais que estão envolvidos para dar conta do retorno destas aos alunos. Para ilustrar, pode-se pensar que uma dúvida em um pequeno grupo pode servir para esclarecer as dificuldades de várias pessoas e pode, ao mesmo tempo, ser elaborada e reelaborada pelo coletivo. Já quando são enviadas individualmente, exigem outro esforço do tutor.

Por outro lado, as dúvidas e os questionamentos feitos em um grupo podem ser compartilhados por todos, o que sugere a reflexão e a formulação de conceitos e opiniões. Nesse caso, não são necessariamente respondidas pelo professor, pois os outros estudantes poderão contribuir na elaboração da resposta. Essa possibilidade de um trabalho mais coletivo mostrou-se bastante limitada no EAD, na instituição pesquisada.

\section{0 trabalho docente do tutor}

Aqui reside uma questão central deste estudo: afinal, qual a diferença do trabalho de um tutor e de um professor? Já se demonstrou que, de acordo com a legislação, são funções do tutor acompanhar as atividades discentes, colaborar na avaliação dos estudantes, manter regularidade de acesso ao AVA e dar retorno às solicitações do cursista, no prazo máxi- 
mo de 24 horas, entre outras tarefas. As funções do tutor ficam bastante claras nas normas legais e nos dados até então expostos sobre a instituição investigada. Mas o questionamento que precisa ser feito é o seguinte: essas também não seriam funções do professor?

Resumidamente, pode-se dizer que, nos cursos pesquisados, ao professor cabe organizar e planejar a disciplina e, em alguns casos, a correção de algumas tarefas. Já ao tutor cabem o esclarecimento de dúvidas, o acompanhamento do aluno e a correção de trabalhos.

Entende-se que há no EAD uma fragmentação do trabalho docente com a inclusão do tutor, que assume algumas tarefas "aparentemente mais simples" no processo de ensino. Entretanto, há uma tentativa de aproximar, pelo menos no discurso, o tutor do professor. Em várias entrevistas, os tutores mencionaram que são chamados de professores, o que representa para eles uma valorização da sua função. Outros afirmaram que são chamados de professores-tutores. De acordo com Rosa: “a nossa coordenação deixa isso muito claro, isso que nós somos valorizados, mas eu vejo que no geral não é, pelo nome tutor, aqui dentro nós somos chamados de professores a distância que é um nome que cabe mais, eu acho, tutor já tem uma forma mais pejorativa".

Todos os entrevistados afirmaram que entendiam o trabalho do tutor como um trabalho docente. Para Osmar: "nós trabalhamos com a parte de ensino, se o aluno faz uma pergunta, e nós temos que responder para ele e pensar como responder, que ele entenda mais facilmente aquela explicação, então volta a parte de ensino”.

Para dizer que sua função é um trabalho docente Isaura ilustra com as atividades que realiza:

O tutor ele não prepara as aulas, tudo bem, mas ele tem todo um acompanhamento, ele tem todo um estudo pra poder auxiliar o aluno da melhor maneira possível, que isso o outro professor também faz [...] toda a questão pedagógica tirando o planejamento, tudo isso nós participamos, nós fazemos os relatórios, nós fazemos as discussões sobre como o aluno tá desenvolvendo as tarefas, qual o desempenho dele, se ele tá melhorando, onde ele tem que melhorar, o que tem que fazer para ser melhorado, então isso aí faz parte, é processo pedagógico.

Vera afirmou que o trabalho do tutor é um trabalho docente: "claro, somos nós que praticamente explicamos tudo pros alunos. A gente 
não tá presencialmente em uma sala de aula, com os alunos sentados ali explicando, só que nós explicamos o conteúdo que está ali”. Quando questionada se o trabalho do tutor é um trabalho docente, respondeu: "sim, uma maneira diferente de ensinar, mas é um trabalho docente". Nesse momento da entrevista, a tutora insistiu em demonstrar o gosto pelo trabalho que realiza no EAD.

Para Vera, não há qualquer dúvida de que o tutor é um professor, pois

os professores pesquisadores, eles colocam aquele material ali, só que tudo cabe a nós, né? Eu oriento meus alunos de como eles vão realizar as atividades, eu ajudo eles no momento em que surgem as dúvidas, porque nós somos os professores, porque o material já vem pronto, mas é nós, conosco que eles conversam, conosco que eles tiram as dúvidas, somos nós que corrigimos as tarefas, então, somos professores.

Nas declarações de Leila, essa proximidade se revelou tão acentuada que a tutora chegou a dizer que já exerceu a função que seria do professor, como, por exemplo, dar aulas: "eu dei aula, dei aula o ano todo".

Justamente pela concepção de que no EAD se concretiza uma forma diferente de ensinar é que a inserção do tutor, nessa modalidade de ensino, ainda parece gerar certa confusão para os profissionais que atuam na área. Os próprios tutores, por verem essa modalidade como nova ${ }^{11}$, acreditam que ela ainda está se estruturando e, consequentemente, que a precariedade do seu trabalho faz parte desse processo inicial de criação e implantação dos cursos.

Para a tutora Isaura, como o curso está começando, logo sairão concursos para os tutores. Mencionou que, no último ano, ocorreu concurso para professor efetivo do EAD e lembrou: "é uma questão que daqui a pouco vai começar a surgir mais, a questão do se sentir desvalorizado, com certeza, porque se eu faço o mesmo trabalho que o outro, por que eu não tenho os mesmos direitos que o outro. Então isso aí vai acabar acontecendo naturalmente".

O fato é que, em um período de cinco anos, o número de vagas no EAD no Brasil cresceu de 24.025, em 2003, para 1.699.489, em 2008², sendo que 1.455.012 dessas vagas ocorreram em instituições do setor privado. Assim, na medida em que a educação se iguala a uma mercadoria 
qualquer, os lucros das empresas que atuam no ramo educacional aumentam em razão de uma exploração maior da força de trabalho. Tendo em vista a inexistente organização dos tutores e a pouca preocupação demonstrada com a realidade que experimentam, é difícil imaginar que "naturalmente" ocorra uma alteração significativa na forma como estão estruturados os quadros profissionais que atuam no EAD.

No setor público, no qual se situa a UAB, a substituição das centenas de bolsistas por professores-efetivos concursados exigiria um pesado investimento do governo federal. Afinal, ao se comparar, por exemplo, o salário inicial de um professor-doutor, com 40 horas de trabalho semanais e dedicação exclusiva ${ }^{13}$, de $\mathrm{R} \$ \mathbf{6 . 7 2 2 , 8 5}$ (mais a parte despendida pelo empregador), com a remuneração do tutor, com 20 horas de trabalho semanais, de $\mathrm{R} \$ 765,00$ (sem qualquer outro custo para o empregador), tem-se uma ideia do volume desse investimento. Disso depreende-se que a precarização do trabalho não ocorre porque se trata de uma modalidade nova de ensino, mas porque falta vontade política para qualificar a educação do país. Não é preciso um estudo para saber se é melhor um bolsista-tutor contratado ou um professor com titulação e concurso para atuar em qualquer nível de ensino.

$\mathrm{Na}$ opinião dos tutores, a própria função é imprescindível ao funcionamento dos cursos, ou seja, sem eles não há EAD. Para Isaura: “o tutor é a figura central, porque sem ele o curso não anda. Claro, as gurias vão organizar, vão planejar, sim, mas se não tiver aquela pessoa para fazer o acompanhamento, não vai funcionar". E ainda afirmou: “o tutor faz o curso funcionar realmente".

Osmar chamou a atenção para um aspecto importante do EAD, de que o trabalho docente nessa forma de ensino é fragmentado, cabendo ao professor planejar e organizar a disciplina e ao tutor, as demais funções: "sem o tutor não tem EAD porque não teria como tirar dúvidas dos alunos, não teria como ajudar na elaboração das questões, correção de tarefas, correção de provas". Rosa mostrou uma compreensão bastante semelhante à de Osmar sobre essa questão:

não existe EAD porque ninguém vai fazer isso, né? O professor pesquisador, o que que ele faz? Ele vai lá, ele pesquisa, ele posta a disciplina no ambiente, e aí, quem é que vai corrigir, quem é que vai dar feedback pro aluno, quem é que vai responder mensagens de dúvidas? É o tutor. Pra mim depois do aluno, é o tutor [na importância]. 
Essa necessidade dos tutores no EAD é o que, na opinião de Vera, garante a eles importância: "eu acredito que seja valorizado porque eles sabem que se nós não estivermos aqui a coisa acaba não andando, eles precisam da gente lá corrigindo provas, ajudando os alunos, nós orientamos como é que estão as atividades, eu acho que é inviável o trabalho sem o tutor".

Esse sentimento de valorização desenvolvido pelos tutores é bastante contraditório, visto que tais profissionais estão permanentemente submetidos a condições precárias de trabalho, conforme já revelou este estudo. O cultivo de um sentimento de aparente valorização apresenta-se, para os tutores, como uma condição para aceitar e suportar vender a força de trabalho nessas condições.

Além da ideia de que o tutor é um profissional imprescindível para o EAD, surgiu, em vários depoimentos, a questão de que é ele quem mais trabalha nessa modalidade de ensino. De acordo com Leila:

Se tu pegares toda a formação da EAD em termos de elaboração do processo, se tu tirares o tutor lá da árvore de construção, tu não tem EAD, tu não tens. E outra, o tutor é o menos remunerado, é o que mais trabalha e é o que leva o curso, porque tem aquele professor que bota as atividades no ambiente, que é o conteudista, que é responsável por olhar as atividades do tutor no ambiente, mas quem é que dá conta das demandas dos alunos? É o tutor. Eu acho que o tutor era para ser o melhor remunerado dentro desse quadro da EAD.

A fala de Leila expressa uma compreensão importante em relação à precariedade da organização do trabalho no EAD, na instituição pesquisada, tanto pela absoluta fragmentação do trabalho quanto pela maior concentração de tarefas e responsabilidades justamente naqueles trabalhadores com menor formação e remuneração.

O discurso de uma formação mais flexível e de uma necessária adaptação às novas demandas do trabalho esteve o tempo todo presente no estudo, tanto em relação aos tutores quanto em relação aos alunos que frequentam os cursos de EAD. Em relação aos tutores, na busca permanente de soluções para as dificuldades que enfrentam, em especial, por não terem formação para o trabalho que realizam. Em relação aos estudantes, na insistência de que os alunos precisam se adaptar a essa "nova modalidade de ensino" e que apenas os mais disciplinados serão bem-sucedidos. Isto é a explícita interiorização do discurso do individualismo, cujo sucesso ou fracasso não é produzido socialmente, mas é responsabilidade de cada um. 
Assim, chega às universidades e aos cursos de formação de professores a exigência de um profissional flexível, polivalente, multifuncional, ou seja, o campo educacional reproduz o mesmo processo de precarização do trabalho assistido em outros setores, nas últimas décadas (ANTUNES, 2001). Entretanto, no caso da educação, esse processo pode ser considerado ainda mais grave, porque a precarização do trabalho no campo educacional produz a desqualificação do ensino.

Os limites de tempo para dedicar à tutoria; a restrita formação (muitas vezes diferente da área em que atua) para o desempenho da função; o tipo de relação estabelecida com o estudante (pautada no esclarecimento de dúvidas e de realização de tarefas) são características encontradas no trabalho do tutor e são indicadoras de que esse tipo de trabalho favorece, no campo educacional, uma prática educativa que não contribui para a intensificação e a complexificação da sociabilidade do indivíduo. Isto é, a interpretação da realidade social, como afirma Reis Jr. (2002), ocorre apenas no plano da aparência.

\section{Considerações finais}

A partir da análise do trabalho do tutor nos quatro cursos de formação de professores oferecidos pela instituição investigada é possível tecer as seguintes considerações:

a) a exigência para ser tutor no EAD, na universidade investigada, é ter curso de graduação, entretanto a análise de documentos legais revelou ser possível o exercício da tutoria em um curso de graduação apenas com o nível médio de ensino. Entre os tutores entrevistados, todos tinham, pelo menos, formação em nível de graduação.

b) a maior parte dos tutores entrevistados possui apenas a graduação. Esse é um aspecto importante, pois, na mesma universidade em que exercem a tutoria, a maioria dos professores que atuam nos cursos presenciais possui mestrado ou doutorado e dedica 40 horas exclusivamente à universidade.

c) alguns tutores atuam em cursos diferentes daqueles em que tiveram formação inicial e trabalham com conteúdos que não fizeram parte de sua formação. 
d) embora a instituição pesquisada seja uma universidade, não se observou, em qualquer momento da pesquisa, um trabalho pautado na integração ensino, pesquisa e extensão. As duas últimas não foram mencionadas como integrantes do processo de formação.

e) a jornada de trabalho semanal dos tutores é longa. Muitos chegam a ter 60 horas ou mais da semana preenchidas com atividades formais, incluindo o trabalho na tutoria, sendo que grande parte deles atua na educação básica na rede pública de ensino.

f) o tutor é um profissional que tem a responsabilidade de fazer o curso funcionar, pois realiza todo o acompanhamento do aluno. Embora, normalmente, não participe do planejamento das disciplinas, é ele quem, por exemplo, esclarece as dúvidas dos alunos e corrige as avaliações. Ficou evidente no estudo que é o tutor quem efetivamente conhece os alunos e quem "segura" o curso.

g) o tutor recebe uma remuneração por meio de uma bolsa e não possui qualquer tipo de vínculo com a universidade que lhe assegure os direitos de qualquer outro trabalhador.

O estudo evidenciou que todas as atribuições dos tutores são funções docentes. O trabalho docente no EAD é fragmentado entre aqueles que planejam e organizam as disciplinas e aqueles que as executam e interagem (virtualmente) com os alunos.

Além desses aspectos, pode-se observar que, mesmo em condições tão adversas, os tutores demonstraram tentar realizar um bom trabalho. Duas interpretações podem ser lançadas em relação a essa questão, a partir de tudo o que se levantou no estudo. Primeiro, a busca pela realização de um trabalho qualificado estaria vinculada ao gosto pelo exercício docente e pelo entendimento da relevância da formação para os alunos. Segundo, tal busca estaria atrelada à criação de uma imagem positiva no interior dos cursos, já que muitos tutores percebem essa função como um trampolim para melhores postos na universidade.

A disciplina, a organização, a dedicação foram apontadas pelos tutores como essenciais para o sucesso do aluno em um curso a distância, bem como para a sua permanência. Indubitavelmente, esses são requisitos fundamentais em qualquer processo de aprendizagem. Porém, no EAD eles ganham maior destaque e conferem ao aluno grande responsabilidade pelo bom desempenho e pela permanência nos cursos. 
Esse discurso precisa ser analisado do ponto de vista do trabalho do tutor, pois pode servir para mascarar a precariedade desse trabalho, na medida em que a qualidade do produto, nessa perspectiva não depende dos meios usados no processo (no caso, ensino-aprendizagem), que inclui a qualidade do trabalho do professor. Essa é uma dimensão importante da análise do trabalho do tutor, pois, ao depositar a maior responsabilidade no aluno, retira-se o foco de todas as condições de ensino que poderão favorecer ou não o sucesso da aprendizagem. Dessa forma, se o trabalho não é o foco, todas as condições precárias do exercício da tutoria, neste estudo demonstradas, não ganham lugar de destaque no EAD e tendem, assim, a se conservar e a se perpetuar.

Por outro lado, se o resultado do processo educacional depende mais do esforço do aluno, o professor não precisa ser muito qualificado, pode ser um tutor. Diferentemente de um objeto que, mal produzido, pode ser substituído ou trocado, no caso da educação, o acesso a um ensino precário será sentido na vida social e não será nefasto apenas para o sujeito que a ele teve acesso, mas a toda a sociedade.

Há, com o EAD, um evidente barateamento da educação no Brasil. Para o setor privado estão criadas as condições para aumentar o lucro auferido pelas empresas educacionais. No setor público, esse tipo de oferta, ao adotar o discurso da "democratização" do ensino, se constitui como mecanismo importante de legitimação política para os grupos que protagonizam a elaboração dessas políticas.

Se a formação em nível superior de professores da educação básica tem sido conduzida por trabalhadores que exercem precariamente esse trabalho, pelos motivos já expostos aqui, questiona-se a possibilidade de ruptura de um círculo vicioso, na educação brasileira, no qual uma parcela muito significativa da população, que, mesmo após ter frequentado vários anos do processo de escolarização, apresenta dificuldades para interpretar um texto ou para realizar operações matemáticas elementares.

Encerra-se este texto com Istvan Mészaros (2005), que pergunta: "para que serve o sistema educacional - mais ainda, quando público se não for para lutar contra a alienação? Para ajudar a decifrar os enigmas do mundo, sobretudo do estranhamento de um mundo produzido pelos próprios homens?” 


\section{Referências}

ANTUNES, Ricardo. Os sentidos do trabalho: o ensaio sobre a afirmação e a negação do trabalho. São Paulo: Boitempo, 2001.

ARROYO, Miguel. Oficio de mestre: imagens e auto-imagens. Petrópolis: Vozes, 2002.

BRASIL. Conselho Nacional de Educação. Câmara de Educação Superior. Parecer sobre diretrizes para elaboração, pelo INEP, dos instrumentos de avaliação para credenciamento de Instituições de Educação Superior para oferta de cursos superiores na modalidade à distância CES-Par. 195/2007, aprovado em 13 set. 2007 (Proc. 23001.000131/2007-67). Brasília, 2007.

BRASIL. Conselho Nacional de Educação. Câmara de Educação Superior. Parecer sobre instrumentos de avaliação para credenciamento de Instituições de Educação Superior para oferta de cursos superiores na modalidade à distância CES-Par. 197/2007, aprovado em 13 set. 2007 (Proc. 23001.000132/2007-10). Brasília, 2007.

BRASIL. Constituição (1988). Constituição da República Federativa do Brasil. Diário Oficial [da] União da República Federativa do Brasil, Brasília, DF, 6 out. 1988.

BRASIL. Decreto n. 1.044, de 21 de outubro de 1969. Dispõe sobre tratamento excepcional para alunos portadores das afecções que indica. Diário Oficial [da] União da República Federativa do Brasil, Brasília, DF, 21 out. 1998.

BRASIL. Decreto n. 2.494, de 10 de fevereiro de 1998. Regulamenta o art. 80 da Lei n. 9.394, de 20 de dezembro de 1996, que estabelece as diretrizes e bases da educação nacional. Diário Oficial [da] União da República Federativa do Brasil, Brasília, DF, 11 fev. 1998. BRASIL. Decreto n. 2.561, de 27 de abril de 1998. Altera a redação dos) arts, 11 e 12 do Decreto n. 2.494, de 10 de fevereiro de 1998, que regulamenta o disposto no art. 80 da Lei n. 9.394, de 20 de dezembro de 1996. Diário Oficial [da] União da República Federativa do Brasil, Brasília, DF, 27 abr. 1998.

BRASIL. Decreto n. 5.622, de 19 de dezembro de 2005. Regulamenta o art. 80 da Lei n. 9.394, de 20 de dezembro de 1996, que estabelece as diretrizes e bases da educação nacional. Diário Oficial [da] União da República Federativa do Brasil, Brasília, DF, 20 dez. 2005.

BRASIL. Decreto n. 5.773, de 9 de maio de 2006. Dispõe sobre o exercício das funções de regulação, supervisão e avaliação de instituições de educação superior e cursos superiores de graduação e seqüenciais no sistema federal de ensino. Diário Oficial [da] União da República Federativa do Brasil, Brasília, DF, 9 mai. 2006.

BRASIL. Decreto n. 5.800, de 8 de junho de 2006. Dispõe sobre o Sistema Universidade Aberta do Brasil - UAB. Diário Oficial [da] União da República Federativa do Brasil, Brasília, DF, 8 jun. 2006.

BRASIL. Lei n. 4.024, de 20 de dezembro de 1961. Fixa as diretrizes e bases da educação nacional. Diário Oficial [da] União da República Federativa do Brasil, Brasília, DF, 28 dez. 1961.

BRASIL, Lei n. 5.540, de 28 de novembro de 1968, que fixa normas de organização e funcionamento do ensino superior e sua articulação com a escola média e dá outras providências. Diário Oficial [da] União da República Federativa do Brasil, Brasília, DF, 29 nov. 1968.

BRASIL. Lei n. 5.692, de 11 de agosto de 1971. Fixa diretrizes e bases para o ensino de 
$1^{\mathrm{O}}$ e $2^{\mathrm{O}}$ graus e dá outras providências. Diário Oficial [da] União da República Federativa do Brasil, Brasília, DF, 12 ago. 1971.

BRASIL. Lei n. 9.394, de 20 de dezembro de 1996. Estabelece as diretrizes e bases da educação nacional. Diário Oficial [da] União da República Federativa do Brasil, Brasília, DF, 23 dez. 1996.

BRASIL. Ministério da Educação. Instituto Nacional de Estudos e Pesquisa Educacionais Anísio Teixeira. Sinopses Estatísticas da Educação Superior - Graduação. Disponível em:

<http://www.inep.gov.br/superior/censosuperior/sinopse/default.asp>. Acesso em: jan.-out. 2010a.

BRASIL. Ministério da Educação. Secretaria de Educação a Distância. Universidade Aberta do Brasil- UAB. Disponível em: < http://uab.capes.gov.br/index.php>. Acesso em jan.set. 2010b.

CONSELHO NACIONAL DE EDUCAÇÃO. Parecer 195, de 12 de julho de 2007. Sobre as diretrizes para a elaboração, pelo INEP, dos instrumentos de avaliação para credenciamento de instituições de educação superior para oferta de cursos superiores na modalidade à distância, nos termos do art. $6^{\circ}$, inciso IV, do Decreto 5.773/2006.

CONSELHO NACIONAL DE EDUCAÇÃO. Parecer 197, de 8 de novembro de 2007. Sobre os instrumentos de avaliação para credenciamento de instituições de educação superior para oferta de cursos superiores na modalidade à distância, nos termos do art. $6^{\circ}$, inciso IV, do Decreto 5.773/2006.

FÉTIZON, Beatriz Alexandrina de Moura; MINTO, César Augusto. Ensino a distância: equívocos, legislação e defesa da formação presencial. Universidade e Sociedade, Brasília, n. 39, p. 93-105, fev. 2007.

MÉSZÁROS, Istvan. A educação para além do capital. São Paulo: Boitempo, 2005.

REIS Jr, João dos. Reforma do Estado e da educação. São Paulo: Xamã, 2002.

STAKE, Robert. Estudos de caso em pesquisa e avaliação educacional. Educação e seleção: Revista da Fundação Carlos Chagas, São Paulo, n.7, p. 5-18, jun. 1983. 


\section{Notas}

1 Nas campanhas utilizadas para divulgar essa modalidade de ensino, é comum a presença de artistas que oferecem sua imagem na venda do produto EAD, igualando o acesso à educação formal a uma mercadoria como outra qualquer.

2 Observou-se, na realização do estudo, que alguns desses critérios não são mencionados nos documentos específicos dessa modalidade de ensino.

3 Todo o debate exposto neste estudo tem como referência os cursos de formação de professores em nível superior, não se relacionando ao trabalho desempenhado pelo tutor em cursos técnicos ou em outras formações.

4 Usa-se a expressão "ensino a distância” em contraposição ao conceito "educação a distância" devido ao entendimento de que os processos não-presenciais, aprovados pelo Ministério da Educação, baseiam-se nos princípios da instrução e da transmissão de informações, o que, de acordo com Arroyo (2002), não assegura o direito ao saber socialmente produzido pela humanidade. Um debate detalhado sobre essa opção conceitual foi desenvolvido por Fétizon e Minto (2007).

5 A regulamentação desse artigo da LDB vai limitar essa oferta, isto é, os níveis iniciais de escolarização não serão oferecidos a distância.

6 Diretrizes para a elaboração, pelo INEP, dos instrumentos de avaliação para credenciamento de instituições de educação superior para oferta de cursos superiores na modalidade a distância, nos termos do artigo $6^{\circ}$, inciso IV, do Decreto n. 5.773/2006.

7 Dispõe sobre os procedimentos de regulação e avaliação da educação superior na modalidade a distância.

8 Em estudo sobre o tema EAD, Giolo (2008) apresenta uma tabela com os seguintes dados sobre as áreas que concentram os cursos de graduação a distância: Formação de professores - 72,3\%; Administração e Gestão - 25,7\%; Outros - 2\%. O levantamento foi feito pelo autor com base nos dados do Censo do Ensino Superior de 2006.

9 Para evitar qualquer tipo de identificação, todos os nomes utilizados no estudo são fictícios.

10 É um meio de contato, entre duas ou mais pessoas, que pode ser usado em vários programas de informática. Pode ser definido como um espaço de encontro virtual.

11 É importante lembrar que já foi citado, no estudo, que o ensino a distância não é novo, mas assume uma nova dimensão no Brasil, nos anos 2000.

12 Dados da Sinopse da Educação Superior (BRASIL, 2010a).

13 Usou-se o exemplo do professor doutor porque a maior parte dos concursos realizados nas instituições federais de ensino superior já exige essa titulação. Quando no concurso é exigida a titulação de mestre, o salário inicial é de $\mathrm{R} \$ 4.442,60$. Dados: www.andifes.org.br 
Recebido: 13/04/2011

Aprovado: 31/10/2011

Contato:

Universidade Federal de Pelotas Escola Superior de Educação Física

Departamento de Ginástica e Saúde

Rua Luis de Camões, 625

Três Vendas

CEP 96055-630

Pelotas, RS

Brasil

Educação em Revista | Belo Horizonte | v.28 | n.02 | p.103-132 | jun. 2012 
